\title{
The Acute Effect of ArmVibration on Eye-Hand Coordination Performance in Youth
}

\author{
Asuman Sahan \\ School of PhysicalEducationand Sports, Akdeniz University, Antalya, Turkey \\ Email: asusahan@akdeniz.edu.tr
}

Received 22 April 2016; accepted 16 May 2016; published 20 May 2016

Copyright (C) 2016 by author and Scientific Research Publishing Inc. This work is licensed under the Creative Commons Attribution International License (CC BY). http://creativecommons.org/licenses/by/4.0/

\section{cc) (i) Open Access}

\begin{abstract}
This study examined the impact of acute arm vibration exercises on hand-eye coordination performance in youths. The subject consisted of 24 male university students. Four sets of Double Hand-Eye Coordination Test (DHECT) were conducted on all participants by performing 60 sec vibration exercises at intervals. After 1-wk, the DHECT (providing 10 sec rest time in between) was performed again on the same participants (control) with four sets at intervals without the vibration application. DHECT results were recorded after both applications. According to the result of repeated measure of ANOVA, DHECT significant improvement was found depending on time measurements with vibration $(p=0.00)$, a significant improvement was not found depending on time in measurements without vibration ( $p=0.17)$.
\end{abstract}

\section{Keywords}

Coordination, Vibration, Youth, Acute, Motor Learning

\section{Introduction}

Vibration exercises provide eccentric and concentric muscle contractions that are rapid and repetitive and increase the metabolic rate (Cochrane, 2011). The vibration exercises are applied in two different ways. The first is a local vibration application and the second is Whole Body Vibration (WBV). In the local vibration application, the vibration is applied on the widest part of the muscle or the tendon with a hand-held vibration source. In the WBV method, attempts are made to increase performance by stimulating the whole body with oscillatory movements on a vibration platform (Issurin, 2005).

When the effects of the vibration were examined, different results were obtained. The reason for this was the 
difference in the amplitude and the frequency that were used in the applications. It is important to set the frequency and the amplitude at an optimum level when organizing the vibration exercises (Brogardh, Flansberj, \& Lexell, 2010; Gerodimos, Zaferidis, \& Karatrantou, 2010; Apple et al., 2010). And in another study, it was proposed that vibration training created the same effects as weight training and that it had a more efficient motor learning effect (Bosco et al., 2000). In order to innerve motor neuron vibration is used as a strong instrument. While examining its use in rehabilitation and sports training, a lot of research has been carried out; by this way motor control is improved (Fattorini, Ferraresi, \& Rodio, 2006).

The literature contains the acute studies which researched the effects that the WBV had on the features that required neuromuscular coordination such as proprioception, reaction speed and balance (Li, Lamis, Wilson, 2008; Hopkins, Pak, Robertslaw, Feland, \& Gage, 2008; Cheung et al., 2007; Jalili, 2011). In the results of a study (20 sec and $5 \mathrm{~Hz}$ ) conducted in order to determine the effects that the WBV had on the body proprioception, an increase of $11.9 \%$ in the position sense of the body flexion was observed as well as an increase of $11.2 \%$ in the peak paraspinal muscle response (Li, Lamis, Wilson, 2008).

It has been argued that the vibration stimulation enables the use of the motor units that are not normally used and that they ease the neuromuscular transmission by increasing the neurotransmitter oscillation via the mechanosensor (the primer afferents in the muscle fibrils) (Armstrong et al., 2008; Nıshıhıra, Iwasaki, Hatta, \& Wasaka, 2002; McBridge, Nuzzo, Dayne, \& Israetel, 2009). It is proven that the vibration induced changes in sensory messages, profoundly influencing the potential motor control of the neurosensory mechanism, lead to the perturbations of sensory motor activities (Martin, Saltzman, \& Elders, 1997).

In studies conducted using different protocols and methods, attempts were made to explain the acute and chronic (6 - 12 months) effects of the vibration exercises on the neuromuscular coordination. The uses of WBV applications, which are generally aimed at increasing lower-body power and strength, have been widely preferred in research. This use especially limits the exercise variations related to the upper body (Issurin, Liebermann, \& Tenenbaum, 1994; Moras, Jimenez, Fajordo, Ranz, \& Mujika, 2010). Some different research tools to produce upper-body or just hand vibration were created in the studies where numerous effects of vibration on the upper-body were analyzed (Gerard \& Martin, 1999; Nepocatych, Bishop, Balilionis, \& Richardson, 2010; Ferguson, Kim, \& Seo, 2013). Earlier studies have usually focused on upper-body neuromuscular performance using feet vibrations. However, studies regarding the effects of upper-body exercises which are done on vibration platform so as to increase performance are really few in number (Martin, Saltzman, \& Elders, 1997).

A few studies examining the impacts of hand vibration applications on the tasks demanding hand-eye coordination have been conducted. In these studies, the alteration of eye movements indicates that vibration is able to affect the coordination of the hand and eye in pointing tasks. Visual control of hand movement is essential in occupational activities requiring precise manipulation. The coordination of eye and hand movements is required in these tasks. Visual proprioceptive and exteroceptive information contribute to the control of complex coordination processes (Gauthier, Vercher, MussaIvaldi, \& Marchetti, 1988). Furthermore, the combination of sensory information (auditory, visual, proprioceptive and tactile) about the arm position enhances hand tracking performances (Nepocatych, Bishop, Balilionis, \& Richardson, 1999).

There is hypothesis in the study that the vibration exercises will increase the double hand-eye coordination performance. Double hand-eye coordination was measured by using the instrument called Lafayette (model 32532, IN, USA). The participants were placed in front of the table where the instrument was located and, they were sat on a chair in a fashion that their hands would be in ergonomic position. The height of the chair was fixed according to the sitting height of the participants and to the height of the participant. First the instrument was introduced to the participants and then, one trial occasion was given to them. The participants were required to begin the test with the "start" command, the duration was initiated and it was terminated when it was reached to the end point. The number of errors and the time parameters (sn) were assessed by performing the test in clockwise and counter clockwise directions. The measurements were repeated twice and the best results of two measurements were assessed. In this study, the acute impact of arm vibration exercise performed in $50 \mathrm{~Hz} 60$ sec and $4 \mathrm{~mm}$ amplitude push-up position above vibration platform on hand-eye coordination has been examined.

\section{Method}

\subsection{Participants}

Twenty-four male students in School of Physical Education and Sport were attended the study. The inclusion 
criteria were standardized health wiling participation and active but not exercising regularly. The exclusion criteria were sudden illness, unwillingness to continue the study.

All subjects have been selected with random method. Each subject signed a statement of informed consent following a full explanation regarding the nature of the experiment. In the study, at the same time, the subject group has been included in the study as the control group after one week for the purpose of terminating the interpersonal learning differences and the impact of learning in DHECT. In this way, the performances of double hand-eye coordination have been measured during the times in which the vibration exercises of the same group have been performed and have not been performed. Vibration exercise easily applicable and noninvasive methods. Therefore, no ethical approval was required.

\subsection{Measures}

Arm vibration exercise on WBV platform: Aspire brand device was used in exercises at $60 \mathrm{sec} 50 \mathrm{~Hz}$ frequency and four mm. amplitude. The vibration applications were performed in a push-up position (elbow flexion position) while the hands were on a platform (Figure 1).

DHECT: Lafayette brand (Model 32532) testing device was used in measuring the double hand-eye coordination. The participants performed the test on start command, while standing in front of the device which was fixed to a table. During the test the individual must follow, in a clockwise direction, the star shape on the test device using a metal pointing stick held in both hands. The participant tries to complete the star shape in the shortest time with the least errors. The test completion time is recorded with a chronometer. In the study, the star completion time has been evaluated as hand-eye performance. Before starting the test, the test methods were explained to the experimental participants and they were allowed to try it out.

Randomized controlled crossover design used in the study. All participants have firstly been applied DHECT. After that, the arms have been placed in the push-up position on WBV platform and $60 \mathrm{sec}$ vibration exercise ( $50 \mathrm{~Hz} 4 \mathrm{~mm}$ ) has been performed. This application has been performed as a total of four sets DHECT and three sets vibration exercises. Hand-eye coordination points of each experimental participant were recorded after each set. After one week of application, the double hand-eye coordination of all the experimental participants (control) was performed in four sets, providing $10 \mathrm{sec}$ of test time in between, and they were measured again and recorded without applying vibration (Figure 2).

\subsection{Data Analysis}

The descriptive statistics for all data obtained from the study were done. The Shapiro-Wilk normality test was used as homogeneity test. For the exercises in which the vibration was applied and not applied, the variance between the four measurements in the DHECT test were compared with the repeated measure of ANOVA to evaluate interactions between time and group. The level of significance was determined as $p<0.05$.

\section{Results}

A significant difference was found in four measurements in the DHECT performed during the time where the arm with vibration exercise was there $(\mathrm{p}=0.00)$. However, while there was significant difference found between the first and the fourth measurements in DHECT when the vibration was applied $(p=0.02)$, there was no significant difference found between the same measurements in DHECT when the vibration was not applied $(p=0.09)$ (Table 1, Table 2).

According to the variance-analysis results in the repeated measurements conducted with DHECT with and without vibration, while significant difference depending on time were observed in measurements with vibration

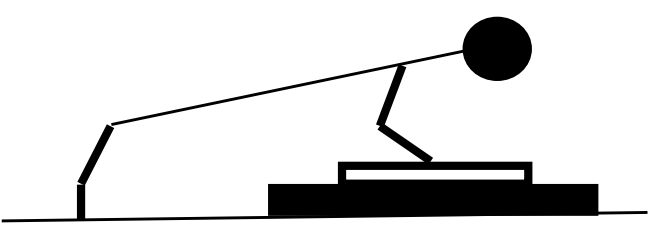

Figure 1. The vibration application in push-up position. 


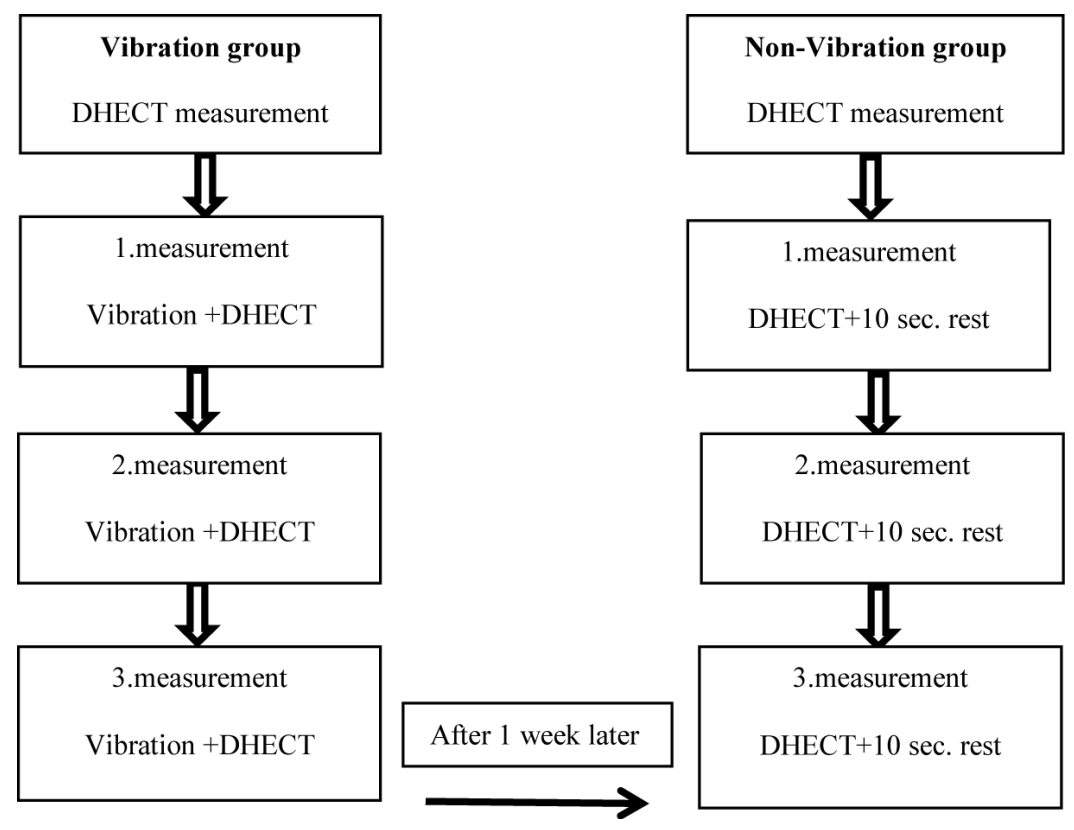

Figure 2. Application procedure.

Table 1. Table descriptive characteristics of study group.

\begin{tabular}{ccccc}
\hline & Mean & Std. Dev. & Min & Max \\
\hline Age (year) & 22.9 & 1.7 & 20.2 & 26.9 \\
Height $(\mathrm{cm})$ & 172.3 & 9.1 & 159.0 & 196.0 \\
Weight $(\mathrm{kg})$ & 63.8 & 12.8 & 44.0 & 93.0 \\
\hline
\end{tabular}

Table 2. Double hand-eye coordination test results.

\begin{tabular}{ccc}
\hline Trails & $\begin{array}{c}\text { Vibration } \\
(\mathrm{M} \pm \mathrm{SD})\end{array}$ & $\begin{array}{c}\text { Non-Vibration } \\
(\mathrm{M} \pm \mathrm{SD})\end{array}$ \\
$1^{\text {st }}$ & $15.01 \pm 6.35$ & $14.13 \pm 5.23$ \\
$2^{\text {nd }}$ & $13.73 \pm 6.44$ & $14.30 \pm 5.15$ \\
$3^{\text {rd }}$ & $13.26 \pm 5.43$ & $14.04 \pm 4.68$ \\
$4^{\text {th }}$ & $12.80 \pm 4.56$ & $13.09 \pm 4.29$ \\
Mean of trials $^{\text {Difference between }}$ & $13.70 \pm 5.54$ & $13.89 \pm 4.67$ \\
Trail $1^{\text {st }}$ and $4^{\text {th }}$ & $\mathrm{t}=3.33$ & $\mathrm{t}=1.79$ \\
Repeated measure & $\mathrm{p}=0.02^{*}$ & 0.09 \\
ANOVA & $\mathrm{F}_{(3,24)}=9.08$ & $\mathrm{p}=0.17$ \\
& $\mathrm{p}=0.00^{*}$ & \\
Group interaction & Interactions and within factor effects & \\
Time & & $\mathrm{F}_{(1,46)}=0.02 \mathrm{p}=0.90$ \\
Group x Time interaction & & $\mathrm{F}_{(3,44)}=5.01 \mathrm{p}=0.04^{*}$ \\
\hline
\end{tabular}

${ }^{*} \mathrm{p}<0.05$.

$(p=0.00)$, it has been observed that there was no significant difference depending on time in measurements without vibration ( $\mathrm{p}=0.17$ ) (Figure 3$)$. 


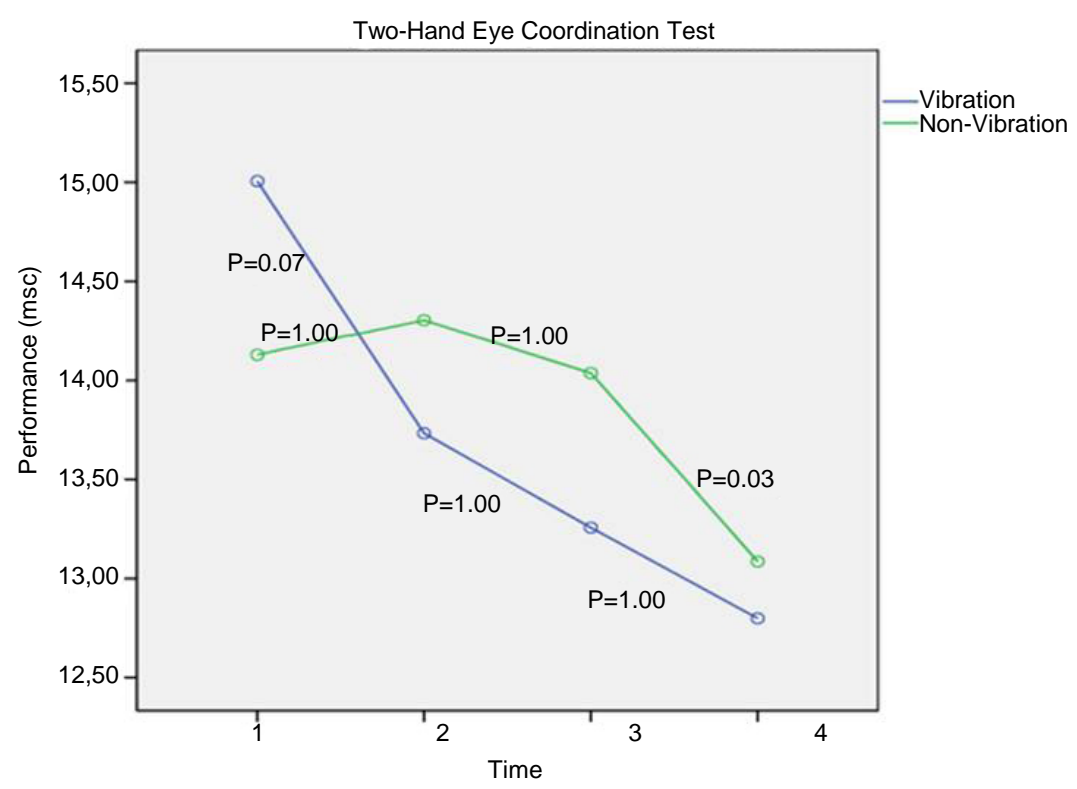

Figure 3. Comparison of DHECT improvement differences between vibration and non-vibration applied here.

\section{Discussion}

The purpose of the study was to determine the impact of vibration exercises performed above WBV platform on the performance of DHEC. No study has been found in the literature in which the impacts of a vibration application performed with similar methods are examined. However, there are previously conducted studies in which the impacts of hand vibration applications are examined.

When all the results were reviewed, it was hypothesized that the vibration exercises would positively affect the hand-eye coordination performance. In the literature there were several studies encountered which researched the effects that the WBV applications had on the hand-eye coordination. In these studies, it was specified that the coordination of the hand-eye movements and the visual, proprioceptive and exteroceptive information required complex coordination processes (Sailer, Flanagan, \& Johansson, 2005). Previous studies have shown that the alteration of continuous manual control resulting from vibration exposure can be attributed to the response of the somesthetic receptors to the vibratory stimulus. These responses contribute to the alteration of the functioning of peripheral and central neurosensory mechanisms underlying motor control (Nepocatych, Bishop, Balilionis, \& Richardson, 2010; Gauthier, Vercher, MussaIvaldi, \& Marchetti, 1998). These changes depend on the frequency which is applied during vibration. A study has been conducted which researched the effects that the hand exposed to a $100-200 \mathrm{~Hz}$ vibration had on motor performance (pointing task). It was indicated that these effects occurred much less than with the high vibration frequency $(200 \mathrm{~Hz})$ (Sailer, Flanagan, \& Johansson, 2005). In a study in which the impact of long term hand vibration in tracking tasks on visuo-manual performance is examined, it has been determined that the vibration application causes a decrease in the time of the tracking task. In addition, it has been found that this decrease becomes more visible as the frequency of vibration decreases (less than $100 \mathrm{~Hz}$ ) (Ferguson, Kim, \& Seo, 2013). Accuracy of limb movement is affected by hand and whole body vibration. Furthermore, oculomanual coordination can also be affected by hand vibration (Nepocatych, Bishop, Balilionis, \& Richardson, 2010). In our study, $50 \mathrm{~Hz}$ arm vibration application caused a decrease in the application time of DHEC task in a similar way.

In the study, immediately after the vibration application ( $50 \mathrm{~Hz} 60 \mathrm{sec}$ ), it was seen that there was an improvement in the hand-eye coordination performance of the experimenting participants. The same improvement can be seen in the measurements which were performed under the same controlled conditions. The reason for this may be that the performance was inept during the first phase of the motor ability learning and the possibility that the task was not easily coordinated. Learning a new skill/ability requires considerable efforts in both the decision mechanism and in the movements that require complex cognitive processes. In this stage, to be able to strengthen the performance or to achieve the purposes, the movements may not be controlled easily. In order for 
the person who is performing the movement to better his/her performance, he/she uses the basic pathways which belong to the sensory and motor signals he/she previously used (Sailer, Flanagan, \& Johansson, 2005). In order to increase performance in this manner, there is no need for new discoveries in first attempts for the task. Previously acquired basic sensory motor rules are used so these tasks can be learned. Exploratory behavior stage is needed in order to increase performance during the acquisition of the abilities which require hand-eye coordination (Sailer, Flanagan, \& Johansson, 2005).

In the present study, it was observed that with the effects of learning the hand-eye coordination performance changed for the better in both measurement periods. However, it is seen that both the performance change graphs are different from each other. While a significant difference was observed between the first and fourth measurements of the coordination performance in vibration measurements, there was no significant difference between the same measurements in non-vibration measurements. This difference shows that the vibration exercises positively affect the double hand-eye coordination development. The studies conducted in the future must indicate the acute or long-term effects of the applications which are performed on different frequencies and intensities.

This difference shows that the vibration exercises positively affect the double hand-eye coordination development. The studies conducted in the future must indicate the acute or long-term effects of the applications which are performed on different frequencies and intensities.

\section{References}

Apple, S., Ehlert, K., Hysinger, P., Nash, C., Voight, M., \& Sells, P. (2010). The Effect of Whole Body Vibration on Ankle Range of Motion and H-Reflex. North American Journal of Sports Physical Therapy, 5, 33.

Armstrong, W. J., Nestle, H. N., Grinnell, D. C., Cole, L., Gilder, E. L., \& Warren, G. S. (2008). The Acute Effect of Whole Body Vibration on the Hoffman Reflex.Journal of Strength and Conditioning Research, 22, 471-476. http://dx.doi.org/10.1519/JSC.0b013e3181660605

Bosco, C., Lacovelli, M., Tsarpela, O., Cardinale, M., Bonifazi, J., Tihanyi, M., \& Viru, A. (2000). Hormonal Responses to Whole Body Vibrations in Man. European Journal of Applied Physiology, 81, 449-454. http://dx.doi.org/10.1007/s004210050067

Brogardh, C., Flansberj, U. B, \& Lexell, J. (2010). No Effects Whole Body Vibration Training on Muscle Strength and Gait Performance in Persons with Late Effects of Polio. Archives of Physical Medicine and Rehabilitation, 91, $1474-1477$. http://dx.doi.org/10.1016/j.apmr.2010.06.024

Cheung, W.-H., Mok, H.-W., Qin, L., Sze, P.-C., Lee, K.-M., \& Leung, K.-S. (2007). High Frequency Whole-Body Vibration Improves Balancing Ability in Elderly Women. Archives of Physical Medicine and Rehabilitation, 88, 852-857. http://dx.doi.org/10.1016/j.apmr.2007.03.028

Cochrane, D. J. (2011). The Potential Neural Mechanisms of Acute Indirect Vibration. Journal of Sports Science and Medicine, 10, 19-30.

Fattorini, L., Ferraresi, A., \& Rodio, A. (2006).Motor Performance Changes Induced by Muscle Vibration. European Journal of Applied Physiology, 98, 79-87. http://dx.doi.org/10.1007/s00421-006-0250-5

Ferguson, S. L., Kim, E., Seo, D., \& Bemben, M. (2013). Comparing the Effects of 3 Weeks of Upper-Body Vibration and Stretching, and Alone on Shoulder Flexibility College-Aged Men. Journal of Strength \& Conditioning Research, 27, 3329-3334. http://dx.doi.org/10.1519/JSC.0b013e31828f27af

Gauthier, G. M., Vercher, J. L., MussaIvaldi, F., \& Marchetti, E. (1988). Oculo-Manual Tracking of Visual Targets: Control Learning, Coordination Control and Coordination Model. Experimental Brain Research, 73, 127-137. http://dx.doi.org/10.1007/BF00279667

Gerard, M. J., \& Martin, B. J. (1999). Post Effect of Long-term Hand Vibration on Visuo-Manual Performance in a Tracking Task. Ergonomic, 42, 314-326. http://dx.doi.org/10.1080/001401399185676

Gerodimos, V., Zaferidis, A., \& Karatrantou, K. (2010). The Acute Effect of Different Whole Body Vibration Amplitudes and Frequencies on Flexibility and Vertical Jump Performance. Journal of Science and Medicine, 13, 438-443.

Hopkins, T., Pak, J.O., Robertslaw, A.E., Feland, J.B., \& Gage, M. (2008). Whole Body Vibration and Dynamic Restraint. International Journal of Sports Medicine, 29, 424-428. http://dx.doi.org/10.1055/s-2007-965362

Issurin, V. B. (2005). Vibrations and Their Applications in Sport. Journal of Sports Medicine and Physical Fitness, $45,324$.

Issurin, V. B., Liebermann, D. G., \& Tenenbaum, G. (1994). Effect of Vibrotory Stimulation Training on Maximal Force and Flexibility. Journal of Sports Science, 12, 561-566. http://dx.doi.org/10.1080/02640419408732206

Jalili, M. (2011). Changes in Balance and Neuromuscular Performance Following Whole Body Vibration and Aquatic Bal- 
ance Training in Elderly Subjects. Annals of Biological Research, 2, 489-495.

Li, L., Lamis, F., \& Wilson, S. E. (2008). Whole Body Vibration Alters Proprioception in the Trunk. International Journal of Industrial Ergonomics, 38,792-800. http://dx.doi.org/10.1016/j.ergon.2007.10.010

Martin, B. J., Saltzman, J., \& Elders, G. (1997). Effect of Vibration Frequency and Duration on Eye-Hand Coordination in Pointing Tasks. Proceeding of 19th International Conference, Chicago, 30 October-2 November 1997, 2793-2798. http://dx.doi.org/10.1109/iembs.1997.756908

McBridge, J., Nuzzo, J. L., Dayne, A. M., \& Israetel, M. A. (2009). Effect of an Acute Bout of Whole Body Vibration Exercise on Muscle Force Output and Motoneuron Excitability. Journal of Strength and Conditioning Research, 24, $184-189$.

Moras, G., Jimenez, S.R., Fajordo, J. T., Ranz, D., \& Mujika, I. (2010). A Vibratory Bar for Upper Body: Feasibility Acute Effect on Emgrams Activity. Journal of Strength \& Conditioning Research, 24, 2132-2142. http://dx.doi.org/10.1519/jsc.0b013e3181aa3684

Nepocatych, S., Bishop, P. A., Balilionis, G., \& Richardson, M. T. (2010).Acute Effect of Upper-Body Vibration on Performance in Master Swimmers. Journal of Strength and Conditioning Research, 24, 3396-3403. http://dx.doi.org/10.1519/JSC.0b013e3181e8a4fe

Nishıhıra, Y., Iwasaki, T., Hatta, A., \& Wasaka, T. (2002). Effect of Whole Body Vibration Stimulus and Voluntary Contraction on Motoneuron Pool. Advances in Exercise and Sports Physiology, 8, 83-86.

Sailer, U., Flanagan J. R., \& Johansson, R. S. (2005). Eye-Hand Coordination during Learning of a Novel Visuomotor Task. The Journal of Neuroscience, 28, 8833-8842. 